\title{
O BINARISMO DE GÊNERO NAS PLACAS DE BANHEIROS EM ESPAÇOS PÚBLICOS
}

\author{
BINARISMO DE GÉNERO EN LAS PLACAS DE BAÑO EN ESPACIOS PÚBLICOS \\ GENDER BINARISM ON BATHROOM BOARDS IN PUBLIC SPACES
}

\author{
Cláudio Eduardo Resende Alves ${ }^{1}$, Maria Ignez Costa Moreira² e \\ Juliana Gonzaga Jayme ${ }^{2}$ \\ ${ }^{1}$ Faculdade Pitágoras, Belo Horizonte/MG, Brasil \\ ${ }^{2}$ Pontifícia Universidade Católica de Minas Gerais, Belo Horizonte/MG, Brasil
}

\begin{abstract}
RESUMO: Este artigo propõe reflexões críticas acerca do binarismo masculino/feminino presente na arquitetura e nas placas identificatórias dos banheiros presentes em espaços públicos. Partindo de um referencial pós-estruturalista das teorias de gênero e diversidade sexual, tomamos como corpo de análise as placas dos banheiros que, por meio de palavras, símbolos e imagens, separam esses espaços, tendo como critério exclusivo o sexo designado ao nascimento e não à identidade autodeclarada de gênero. Nesse contexto, a ambiguidade e a fluidez presentes em corpos trans atuam como significativos elementos de denúncia dos limites normativos da classificação dos banheiros, colocando em xeque territórios legitimados socialmente como masculinos e femininos. Assim, as placas são consideradas como analisadores institucionais, pois desvelam a disputa entre forças instituintes e forças instituídas, a qual mostra que, apesar das normativas legais brasileiras, a institucionalização do reconhecimento das diversas formas de ser homem e de ser mulher ainda é objeto de tensão.

PALAVRAS-CHAVE: Banheiro; Gênero; Pessoas trans; Políticas públicas.
\end{abstract}

RESUMEN: Este artículo propone reflexiones críticas sobre el binarismo masculino/femenino presente en la arquitectura y sobre las placas de los baños presentes en los espacios públicos. Partiendo de un referencial postestructuralista de teorías de género y diversidad sexual, tomamos como cuerpo de análisis las placas de los baños que, a través de palabras, símbolos e imágenes, separan estos espacios, teniendo como criterio exclusivo el sexo designado al nacer y no la identidad de género auto declarada. En este contexto, la ambigüedad y la fluidez presentes en los cuerpos trans actúan como elementos significativos de denuncia de los límites normativos de la clasificación de los baños, poniendo en jaque territorios socialmente legitimados como masculinos y femeninos. Así, las placas son consideradas como analizadores institucionales, pues revelan la disputa entre fuerzas instituyentes y fuerzas instituidas, lo que muestra que, a pesar de las normas legales brasileñas, la institucionalización del reconocimiento de las diversas formas de ser hombre y de ser mujer sigue siendo objeto de tensión.

PALABRAS CLAVE: Baño; Género; Personas trans; Políticas públicas.

ABSTRACT: This article proposes critical reflections on the male/female binarism present in the architecture and in the identification boards of the bathrooms in public spaces. Based on a post-structuralist framework of the theories of gender and sexual diversity, we take as body of analysis the bathroom signs that, through words, symbols and images, separate these spaces having as exclusive criterion the designated sex at birth and not the self-declared gender identity. In this context, the ambiguity and fluidity present in trans bodies act as significant elements of denunciation of the normative limits of the classification of bathrooms, putting in question socially legitimized territories as male and female. Thus, the signs are considered as institutional analyzers, because they reveal the dispute of the instituting forces and the instituted forces, which shows that, despite the Brazilian legal norms, the institutionalization of the recognition of the various forms of being a man and being a woman is still object of tension.

KEYWORDS: Bathroom; Gender; Transgender people; Public policies. 


\section{Introdução}

Este artigo apresenta algumas reflexões críticas acerca do binarismo claustrofóbico masculino/feminino presente na arquitetura e nas placas identificatórias dos banheiros de espaços públicos. Partindo de um referencial pós-estruturalista das teorias de gênero e diversidade sexual, tomamos como corpo de análise as placas dos banheiros disponíveis em escolas, repartições públicas, bares, restaurantes e shopping centers, decifrando-as como evidência do descompasso entre as normativas jurídicas e sanitárias e as múltiplas formas de ser homem e de ser mulher na sociedade contemporânea (Butler, 2018; Junqueira, 2010; Miskolci, 2012; Preciado, 2017b).

As placas dos banheiros em locais públicos revelam a divisão desses lugares pela lógica binária e cis-heteronormativa, demarcando, por meio de imagens, palavras e símbolos, os territórios legitimados socialmente do masculino e do feminino, tendo como concepção fundante e falaciosa o universalismo do sujeito homem e do sujeito mulher. O texto propõe pensar as placas de banheiros como analisadores institucionais (Lourau, 1975), pois desvelam conflitos e contradições, evidenciando o hiato entre a classificação normativa e o reconhecimento do efetivo direito de uso dos banheiros públicos segundo a identificação de gênero de cada pessoa.

Nesse contexto, pessoas trans, terminologia escolhida para referenciar pessoas travestis, transexuais e transgêneros (Alves, 2017), denunciam os limites normativos da classificação das placas de banheiros, pois seus corpos ambíguos não se enquadram (Butler, 2016) e embaralham (Louro, 1997) as normas de gênero. A incongruência entre o nome, a identidade de gênero e a estética corporal é motivo de sofrimento psicossocial, pois desencadeia, muitas vezes, ações de preconceito e discriminação transfóbica, entre elas a proibição do uso de determinados banheiros por pessoas trans (Alves, 2017; Andrade, 2015; Bento, 2012).

O artigo está organizado em quatro seções: $1^{\text {a }}$ Seção: Nome, gênero e corpo: incongruências no uso do banheiro por pessoas trans; $2^{a}$ Seção: Banheiro como analisador institucional: uma categoria analítica; $3^{\text {a }}$ Seção: A linguagem das placas sinalizadoras dos banheiros: concepções normativas; e $4^{a}$ Seção: Considerações em trânsito.

\section{Nome, gênero e corpo: incongruências no uso do banheiro por pessoas trans}

No Brasil, o início dos anos 2000 foi caracterizado por uma significativa articulação entre os movimentos sociais feministas, LGBT e a academia, que exigiram do Estado brasileiro a formulação e a implantação de políticas públicas no campo da educação, saúde e assistência social, destinadas à proteção, defesa e restituição de direitos humanos, civis e sociais de mulheres, gays, lésbicas, transexuais e travestis. A população trans alcançou, na primeira década do século XXI, maior visibilidade e espaço para apresentar e discutir suas reivindicações específicas, entre elas o direito de mudança do nome próprio no registro civil, e, então, de portar documentos que apresentassem coerência entre o nome e sua identidade de gênero. 
Entre as conquistas, podemos destacar a prerrogativa legal do uso do nome social que representa sua identidade de gênero até a publicação do Provimento n. ${ }^{\circ}$ 73/2018, do Conselho Nacional de Justiça, que prevê a averbação da alteração do nome e do gênero/sexo nos registros de nascimento de pessoas trans nos cartórios do Brasil, por meio exclusivo da autodeclaração. E, em 2019, a transexualidade deixou de figurar como transtorno mental no Código Internacional de Doenças (CID).

Podemos considerar que a ação dos movimentos sociais (feministas e LGBT) teve força instituinte, ou seja, esses movimentos mobilizaram energias produtivas, desejantes e revolucionárias, capazes de inventividade e de transformação de instituições sociais já existentes e aparentemente cristalizadas como o aparato jurídico do Estado. Apesar dos avanços, é fundamental que o processo de institucionalização seja acompanhado de ações concretas, de organizações que materializam a nova ordem, de modo que essa deixe de causar estranheza e que os novos direitos estejam estabelecidos, instituídos sem que necessitem de ações especiais para serem reconhecidos (Baremblitt, 1992).

Neste artigo, no âmbito da discussão dos processos de institucionalização em busca de uma equidade de gênero nas políticas públicas, identificamos, nas placas dos banheiros públicos, um potente argumento de problematização, pois o uso do banheiro binário permanece como um grande desafio para pessoas trans. Desse modo, um ato que deveria ser prosaico, como usar o banheiro, é, muitas vezes, uma situação absolutamente constrangedora a pessoas trans, especialmente àquelas com baixa passabilidade. ${ }^{1}$ Ao discutir sobre o tema, Cavalcanti (2016) usa a imagem de uma régua regulatória que definiria níveis de feminilidade e masculinidade das performances de gênero. Quanto menos "passável", maior constrangimento para decidir qual banheiro usar, sendo comum ouvir relatos de pessoas trans que deixam de usar banheiros públicos.

O problema do uso dos banheiros por pessoas trans se tornou objeto de inúmeras investigações no campo dos estudos pós-estruturalistas de gênero: Junqueira (2010), Miskolci (2012); Alves e Moreira (2015); Oliveira e Maio (2016), para citar apenas estudos realizados no Brasil. Halberstam (1998) dedica um tópico ao que ela chama de paradigma do banheiro, em que discute a complexa escolha do banheiro por pessoas trans, cujo corpo é tido como um retrato da inadequação entre o sexo e o gênero.

As pessoas trans, como se sabe, são pensadas, muitas vezes, em uma zona de abjeção - conceito usado aqui no sentido de Butler, como aquelas zonas onde estariam os corpos que não importam (Butler, 2003, 2005) —, mas, se quisermos ver, perceberemos que elas explicitam o fato de que as masculinidades e as feminilidades não são naturalizadas; elas embaralham justamente a concepção binária do gênero. No discurso biologizante e universalista da Medicina, uma pessoa trans é apenas quem realizou ou deseja realizar a cirurgia de redesignação sexual. No entanto, na experiência cotidiana, há pessoas que vivem diferentes experiências de ser trans, e todas elas deveriam ter o direito de ser chamadas (nomeadas) como quiserem e de usar o banheiro que identificam como adequado a seu gênero.

De acordo com Lauretis (1994), o gênero é construído por meio de tecnologias, como o cinema, e de discursos institucionais, como narrativas teóricas, que podem reforçar os estereótipos do que seria feminino e masculino, pois promovem certas representações de gênero. Partindo dessa discussão, Preciado (2017a) afirma que a arquitetura também opera como uma tecnologia de gênero, produzindo a verdade da masculinidade e da feminilidade. 
O autor corrobora a discussão de Halberstam (1998), para quem os banheiros públicos devem ser pensados como lugares de inspeção da adequação de corpos às normas de masculinidade e feminilidade. As portas dos banheiros públicos carregam um símbolo (feminino ou masculino), que é uma interpelação de gênero, como se o banheiro fosse um lugar mais próprio para refazer o gênero do que para fazer necessidades fisiológicas. Em um banheiro público feminino, por exemplo, as próprias mulheres atuam como fiscais de gênero: se existe a suspeita de que uma pessoa tem um pênis, esta se torna imediatamente alvo de vigilância das usuárias. Na sequência, as mulheres buscam pistas da ambiguidade do corpo, como cabelo curto, roupas pouco femininas, ausência de maquiagem, forma de andar, entre outras. Tudo em busca de garantir que apenas mulheres ditas verdadeiras possam usar o banheiro feminino. Mas, afinal, o que seria uma mulher verdadeira?

Pessoas trans ou mesmo aquelas que não sejam suficientemente femininas ou masculinas para o padrão hegemônico continuam sendo vistas como menos humanas, haja vista o constrangimento na escolha do banheiro ou na possibilidade de permanência no banheiro escolhido. No fim das contas, talvez essas conquistas sejam importantes para reiterar a existência dessas pessoas, mas o fazem com base na normatização dessa existência, e essa norma se mantém dentro de uma matriz binária e heterossexual. Apesar de essa norma ser binária e heterossexual - que patologiza o ambíguo e, de acordo com Preciado (2017b), inventa a divisão sexual binária, construindo, de forma absolutamente artificial, o que chama de normalidade - a experiência revela que há uma infinidade de vidas que escapam do binarismo. Para Halberstam (1998), aliás, o banheiro revela exatamente essa multiplicidade de experiências, pois a quantidade de vezes que mulheres que se apresentam como desviantes de gênero são confundidas nos banheiros públicos mostra, a um só tempo, como o gênero é policiado dentro dos banheiros e como não há um único padrão de mulher. Na tese de doutorado intitulada "Travestis, Transformistas, Drag-queens, Transexuais: Personagens e máscaras no cotidiano de Belo Horizonte e Lisboa" (Jayme, 2001), Jó e Porcina, interlocutoras da pesquisadora, mostram, em suas falas, a artificialidade da norma binária:

Jó: O que é um transgender? Um transgender é uma palavra, não é nada mais do que isso. É uma palavra onde estão englobados vários géneros diferentes, que são aqueles géneros que não se enquadram naquilo que é socialmente correto: que é o género masculino e o género feminino. Estes são os que socialmente são os únicos aceitos, há, no entanto, muitos outros, como seja: os transexuais, os travestis, os cross-dresser, os andróginos e os hermafroditas. Isto é uma palavra, é uma única palavra que engloba vários géneros, que não o masculino e o feminino, e que podem ser inclusivamente os dois, juntos. (Jayme, 2001, p. 241)

Porcina: Eu me acho normal, eu me acho uma pessoa normal. Por que eu digo que eu sou normal? Tem gente que fica apavorada de eu sair na rua assim, eu digo, meu Deus do céu, isso aqui é um body, isso foi feito para mulher usar, porque existe confecção masculina, feminina e infantil, não existe confecção para travesti. ... Por que a mulher pode usar e eu não posso? (Jayme, 2001, pp. 241-242)

Parece que está clara aqui a ligação intrínseca entre nome, corpo, identidade, ou seja, não é possível imaginar que corpo e mente são dissociados. Pode-se pensar que as pessoas trans não tenham o nome como designador rígido (Bourdieu, 1997), já que, muitas vezes, 
é comum que esses nomes sejam alterados ao longo do tempo (como também a manutenção de mais de um nome, consoante o contexto), e essa mudança não estaria vinculada apenas a uma ou múltiplas novas construções de gêneros. Isso não quer dizer, no entanto, que o nome próprio não seja importante para esses sujeitos. Pelo contrário, é fundamental, inclusive no sentido de manutenção da identidade, ainda que isso possa parecer paradoxal. Segundo Csordas (1990), as reflexões contemporâneas sobre o corpo, incorporação ou corporificação, fazem-se no sentido de não dissociar o corpo e a mente. O corpo, a um só tempo, significa e age. Assim, a pessoa é instável, não fixa, porque construída e reconstruída permanentemente, mas pessoa é uma categoria que inclui a consciência e o corpo, e que revela relações sociais. Laqueur (2001) aponta para a ressignificação que o corpo vem adquirindo ao longo da história da humanidade, em especial no período pós-Idade Média, quando o corpo sexuado ganha espaço na cultura, tornando-se objeto de investigação científica e artística.

De acordo com Kofes (2010), um dos aspectos fundamentais do gênero para pensar as relações sociais refere-se ao fato de que essa categoria tanto pode revelar a crença de uma oposição dicotômica entre os sexos quanto embaralhar essa oposição. As pessoas trans ora operam com essa dicotomia, ora a explodem, revelando como a subjetividade, o gênero e a própria identidade são múltiplos e construídos performativamente, embora nem sempre essa multiplicidade seja aceita, ainda mais se for incorporada de maneira muito visível e percebida como diferente da imagem dúplice do sistema sexo/gênero (Rubin, 1975). Apesar de existirem, de circularem pelas ruas, pelas escolas, pelos postos de saúde, pelos banheiros públicos, pessoas trans ou fluidas, ou que não tenham um corpo visto como estando em acordo com a norma, na maioria das vezes, não são traduzíveis. Socialmente não aceitas, é como se não existissem, são desumanizadas por não se enquadrarem na lógica binária e cis-heteronormativa, termo usado para se referir, criticando, à ordem (norma) sexual contemporânea, cisgênera e heterossexual, que se materializa nas placas de banheiro.

\section{Banheiro como analisador institucional: uma categoria analítica}

O conceito de analisador institucional foi proposto por Lourau (1975), que o concebe como ferramenta de análise dos coletivos institucionais, cujo manejo revela as contradições e as tensões entre as forças instituídas e instituintes. Para Lourau, analisadores possibilitam "Revelar a estrutura da organização, provocá-la, forçá-la a falar" (p. 303). Segundo o autor, os analisadores podem ser construídos pela intervenção do analista institucional, que provoca a emergência da contradição, e, quando produzidos pelo grupo, pelo cotidiano, são considerados espontâneos. As placas dos banheiros podem ser consideradas espontâneas, pois não foram construídas deliberadamente para revelar uma contradição; antes, são tomadas como naturais, assim como natural é considerada a diferença entre os sexos anatômicos, portanto são postas sem questionamento.

As placas dos banheiros em locais públicos revelam a divisão desses lugares pela lógica binária e cisheteronormativa. E, nesse sentido, são tomadas como analisadores, pois revelam contradições e desmascaram os conflitos. Uma pessoa que tem um corpo com pênis, mas que se apresenta com um nome feminino, que tem documentos com a explicitação de seu nome social ou documentos civis nos quais está registrado um nome feminino e que 
está vestida com roupas femininas é impedida de usar o banheiro feminino ou uma pessoa que se identifica como homem, traz em seu corpo marcas estéticas consideradas masculinas, mas que não tem um pênis, e sim uma vagina será igualmente impedida de entrar em banheiro masculino ou será policiada (e, algumas vezes, denunciada) por outras mulheres que parecem estar ali para policiar o gênero (Halberstam, 1998; Preciado, 2017a). São raros os espaços públicos, nas cidades brasileiras, onde possam ser encontrados banheiros sem indicação de sexo ou que estampem placas que apontam para ambos os sexos.

$\mathrm{O}$ analisador revela o hiato entre a nomeação e o reconhecimento do efetivo direito de uso dos banheiros públicos segundo a identificação de gênero. Isso faz pensar que há ainda uma pressão social para o exercício binarista de gênero como condição para a livre circulação em lugares públicos.

Interessante também observar que, além das placas "masculino" ou "feminino" dos banheiros, há uma variedade de expressões gráficas, para além das palavras, usadas para interpelar o gênero e que revelam a força da lógica cisheteronormativa e binária no imaginário social. Por exemplo, na porta de um banheiro feminino de um restaurante, vê-se uma rosa, seguida da palavra "rosa"; ao lado, no banheiro masculino, a imagem de um cravo, seguida da palavra "cravo". Essa placa, a um só tempo, afirma que há lugares prescritos (e separados) para homens e mulheres, sugere sentidos desiguais e assimétricos para as relações de gênero, pois há uma cantiga popular brasileira que atravessou gerações nas brincadeiras de roda que diz: "O Cravo brigou com a Rosa debaixo de uma sacada; o Cravo saiu ferido, e a Rosa, despedaçada”. Em uma sorveteria, local frequentado por pessoas de várias idades e muitas crianças, o banheiro feminino é casquinha e o masculino é cascão (Figura 1). No diminutivo e no aumentativo se informa a desigualdade da força entre homens e mulheres. Essas placas jocosas e que apelam para as memórias de infância de adultos e de idosos revelam-se analisadores que denunciam a tentativa de ocultar as desigualdades, os jogos de força e de dominação tomados como naturais.

\section{Figura 1. Placas de banheiro: Escrito "Cascão" com figura de um homem azul e escrito "Casquinha" com figura de uma mulher vermelha}
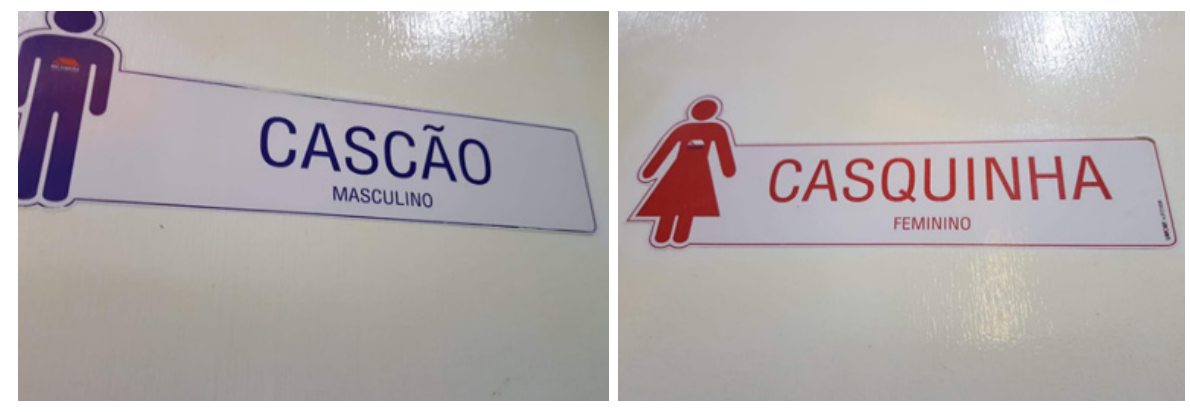

Retomando Lourau (1975), encontramos sua afirmação de que o "analisador é sempre material. E o corpo é um analisador privilegiado. A institucionalização entre meu corpo e o sistema de objetos é o que revela mais cruelmente a instância econômica do sistema institucional" (p. 284). As placas dos banheiros oferecem a materialidade da organização binária da sociedade. Os corpos que não se adéquam a tal ordem binária são proscritos, descartados, não têm lugar. Os banheiros revelam os corpos no espaço construído para ocultá-los. 


\section{A linguagem das placas sinalizadoras dos banheiros: concepções normativas}

Ao nascer, um evento linguístico marca nossa chegada: "é um menino" ou "é uma menina". Nascemos inseridos numa linguagem e numa cultura preexistentes. Desde o nome, nosso dispositivo identificatório começa a revelar presença, apontando para sexo, gênero, idioma, classe social, localização geográfica e família preexistentes. Para Butler (2018), são momentos discursivos, como a anunciação do nascimento de um menino ou de uma menina, que originam nossa vida classificada pelo gênero. Os chamados atos de fala dão existência àquilo que anunciam, pois a linguagem é uma ação potente no mundo. Atos de fala podem ser compreendidos como modos de pensar e julgar (Butler, 2018), determinando o limite entre o legítimo e o abjeto, entre os modos viáveis e os desprezíveis de ser e de estar. Afinal, quais seres humanos são dignos de reconhecimento e, portanto, de uma vida vivível?

A partir do ato de fala inaugural de nossa existência, somos introduzidos num mundo imerso de normas de gênero. Elas nos são apresentadas e inculcadas, seguem-nos pela vida toda, marcam-nos, afetam-nos, estigmatizam-nos e, principalmente, produzemnos. O exercício de gênero é sempre uma negociação com o poder instituído, é sempre performativo. Gênero e sexualidade são performativos, assim como seus discursos e articulações políticas. A teoria da performatividade de gênero de Butler (2003, 2005, 2018) propõe uma reflexão crítica sobre a normatização da vida e a subversão das regras sociais e políticas de existência. "A performatividade é um modo de nomear um poder que a linguagem tem de produzir uma nova situação ou de acionar um conjunto de efeitos" (Butler, 2018, p. 35).

Partindo do elemento arquitetônico banheiro e de suas regras de uso conforme o gênero, torna-se possível realizar uma série de reflexões críticas, em especial, a partir das placas sinalizadoras dos banheiros masculino e feminino encontradas em espaços públicos e privados. Tais placas, como signos linguísticos, apontam para performances de gênero, ou seja, efeitos discursivos de gênero produzidos e impostos por práticas reguladoras de coerência, na maioria das vezes, binárias e excludentes, por meio de imagens, desenhos, fotos, escritos e outras representações do universo feminino e do universo masculino. As placas de banheiro podem ser lidas como atos de fala (Butler, 2018), visto que sua decodificação imagética institui uma ação normativa de separação entre os campos de pertencimento do homem e da mulher, numa perspectiva naturalizante, tendo como referencial a demarcação de pares opostos conforme o gênero.

Sendo o discurso situado, é possível refletir sobre os atos regulatórios acerca da exposição dos corpos em diferentes espaços privados e públicos. A família ensina às crianças que o banheiro doméstico é unissex, portanto a placa é desnecessária, mas elas também aprendem que esse é um espaço reservado e se deve fechar a porta durante o uso. Na escola, a divisão binária dos banheiros, demarcando as diferenças entre meninos e meninas com base no critério genital, possibilita a vigilância para coibir possíveis jogos sexuais. No espaço público mais amplo, a divisão binária se estabelece também por meio do critério genital, afirmando a lógica cisheteronormativa.

No entanto, conforme os corpos trans alcançam visibilidade, a equação linear entre o sexo de designação no nascimento e a identidade de gênero é posta em xeque e, ao mesmo tempo, movimentos sociais incorporam a pauta da luta pelos direitos das pessoas trans, 
alcançando algumas vitórias que concorrem para superar a exclusão e a discriminação. Um desses direitos foi trazido por meio de políticas públicas que visam a garantir o uso do banheiro por pessoas trans conforme sua identidade de gênero (Resolução n. 12/2015).

O banheiro consiste num local emblemático de configuração das diferenças, um espaço demarcado por descobertas, segredos, mistérios e jogos sexuais (Teixeira \& Raposo, 2007). A organização dos banheiros funciona como uma tecnologia de gênero (Preciado, 2017a), isto é, um elemento de regulação da masculinidade e feminilidade com base na heterossexualidade compulsória. Segundo Preciado (2017b), o ato de entrar no banheiro binariamente demarcado valoriza mais o gênero do que as necessidades fisiológicas, enfatizando a expressão da sexualidade em detrimento dos atos de urinar e defecar, inerentes a todo ser humano.

As placas de sinalização dos banheiros partem de um princípio universalista do sujeito homem e do sujeito mulher e, como decorrência disso, exploram signos ditos masculinos em contraposição aos ditos femininos. As imagens de placas de banheiro selecionadas para análise foram coletadas aleatoriamente mediante fotografias produzidas por meio de aparelhos celulares em diferentes espaços públicos, entre os anos de 2017 e 2019. No que se refere ao território, com exceção da Figura 1, registrada em Poços de Caldas-MG, e das Figuras 15 e 16, que pertencem a uma campanha do Conselho Nacional de Combate à Discriminação e Promoção dos Direitos LGBT (Resolução n. 12/2015), as demais foram feitas na cidade de Belo Horizonte-MG: Figura 1: sorveteria; Figuras 2 a 12: bares e restaurantes; Figura 13: Secretaria Municipal de Políticas Sociais da Prefeitura de Belo Horizonte; Figura 14: boate LGBT; Figuras 15 e 16: campanha nacional LGBT; Figuras 17 e 18: shopping center; e Figura 19: escola municipal.

As figuras indicam, além da divisão dos espaços pela ótica binária, os estereótipos de gênero: enquanto homens tomam cerveja, mulheres tomam vinho (Figura 2); enquanto homens são objetivos e falam pouco, mulheres são falantes e prolixas (Figura 3); enquanto homens são perigosos, portanto Lobo Mau, mulheres são frágeis como a Chapeuzinho Vermelho (Figura 4). Dessa forma, a placa sinalizadora como um ato de fala anuncia quais sujeitos têm existência de gênero reconhecida e são autorizados a usar o banheiro que lhes são adequados. Contudo, qualquer homem ou mulher, cisgênero ou transgênero, que não se encaixe nesse enquadramento (Butler, 2016) torna-se dissidente da norma de gênero, portanto inserido numa situação de precariedade, ou seja, "Numa situação politicamente induzida na qual sofrerá com a deterioração de redes de apoio sociais e econômicas" (Butler, 2018, p. 40).

Figura 2. Placas de banheiro: Garrafa de cerveja simulando genital masculino e taça de vinho simulando genital feminino

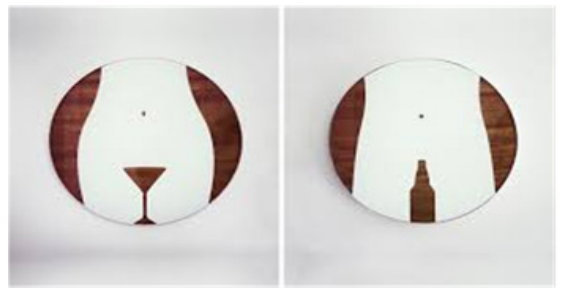




\section{Figura 3. Placas de banheiro: Escrito numa porta branca "Blá” e na outra porta} "Blá/Blá/Blá/Blá/Blá"

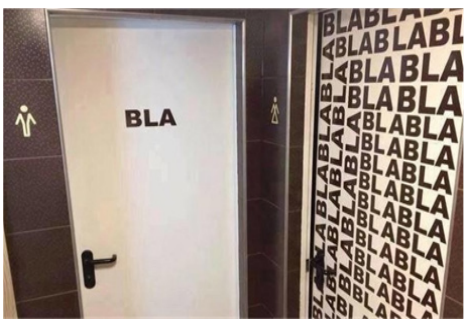

Figura 4. Placa de banheiro: Imagens do chapeuzinho vermelho e lobo mau sobre fundo azul

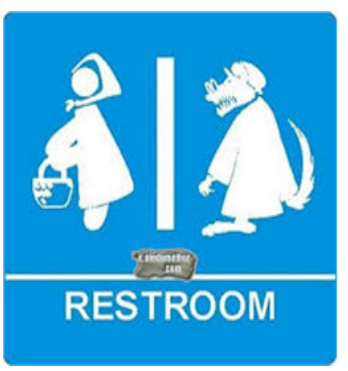

A incorporação das normas de gênero ocorre com base na conformação corporal, a anatomia e a fisiologia, dela oriundas, tornam-se legitimadoras do ser homem e do ser mulher. Assim, podemos indagar se, para usar o banheiro masculino, é condição sine qua non ter pênis e, para usar o banheiro feminino, ter vagina e, além de possuí-los, é necessário "provar", via performatividade, que os têm. O sexo anatômico é celebrado como uma ficção fundante da sexualidade e das expressões de gênero na sociedade. A biologia é balizada como destino. Do simples uso de um banheiro (ou ao menos esse uso deveria ser simples), uma rede de significados, identificações e legitimações do masculino e do feminino são construídas e colocadas em xeque. O banheiro atua como uma espécie de balizador de gênero (Alves, 2017), dividindo em duas alternativas ancoradas no genital e no sistema excretor dele decorrente.

O falocentrismo (Butler, 2003), como instituidor da matriz cisheteronormativa, tem papel importante em algumas representações de feminino e masculino nas placas de banheiro. O corpo da mulher é marcado com base num discurso masculino, sendo o corpo do homem em estado de fusão com o universal. As placas sinalizadoras dos banheiros reiteram a assimetria hierárquica entre homens e mulheres, evidenciando o pênis como designo masculino e sua ausência como feminino (Figura 5). Também são utilizados outros artifícios linguísticos fálicos, como o cachorro-quente com salsicha para o homem e o cachorro-quente sem salsicha para a mulher (Figura 6); a orientação do jato urinário, sendo o do homem potente, com emissão a longa distância, e a mulher fraca, com o derramamento reto da urina no chão (Figura 7); o uso de animais, sendo o peru para o homem e a perereca para a mulher (Figura 8); e ainda a representação da mesquita fálica para homem e da mesquita como apologia aos seios para mulher (Figura 9). 
Figura 5. Placas de banheiro: Letra “i” minúscula com e sem saliência lateral sobre a superfície de portas pretas
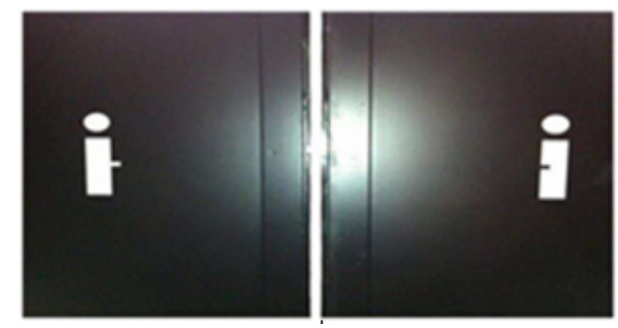

Figura 6. Placas de banheiro: Escritos "Boys" e "Girls" com imagem de cachorro quente com e sem salsicha

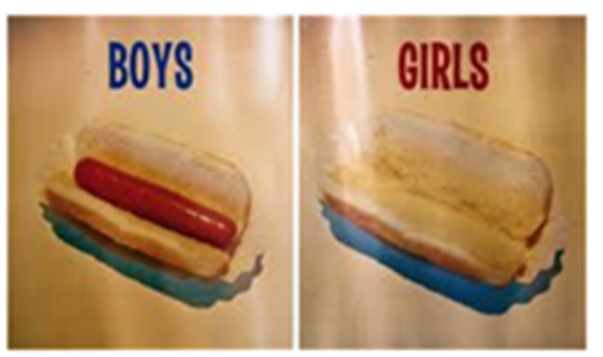

Figura 7. Placas de banheiro: Líquido amarelo escorrendo da maçaneta numa porta preta e do buraco da fechadura em outra porta
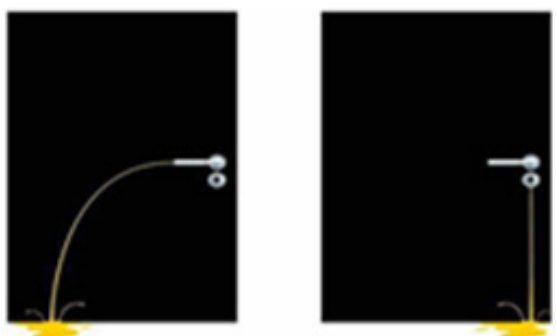

Figura 8. Placas de banheiro: Figuras dos animais perereca e peru de cor preta sobre fundo branco
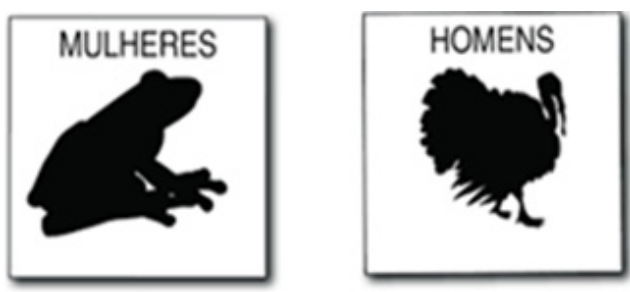
Figura 9. Placas de banheiro: Dois tipos diferentes de mesquitas árabes - uma com torre e outra sem torre, sobre fundo laranja

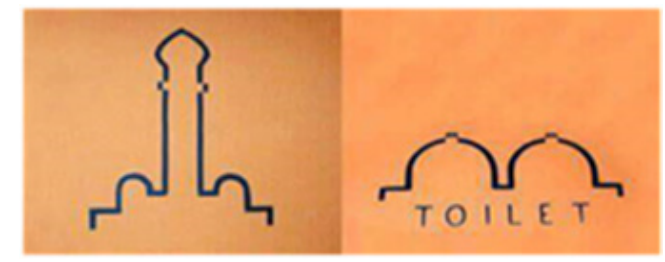

Sobre a normatização definidora do binarismo que reconhece e legitima alguns corpos enquanto apaga e deslegitima outros, Butler pontua que um dos primeiros passos no processo de estranhamento das normas é "Perguntar como essas normas são instaladas e normalizadas é [não] tomar a norma como algo certo ... não deixar de perguntar como ela foi instalada e representada, e à custa de quem" (Butler, 2018, p. 44). O estranhamento das normas de gênero é algo desejável e necessário, a fim de romper com o enquadramento claustrofóbico delimitador, evitando o apagamento e a precarização de sujeitos e corpos.

Ainda no campo anatômico, é importante destacar a presença de representações de seios em certas placas de banheiro como elemento feminino, ainda que um feminino idealizado. Ter seios baliza o corpo de uma mulher verdadeira? Mas como empregar esse raciocínio em corpos de mulheres que retiraram seios em razão de câncer ou mesmo corpos de alguns homens trans que optam em manter os seios? Tais reflexões relativizam as performances de gênero, tomadas como monolíticas. Em outros bares e restaurantes, algumas placas representam os seios em certo grau de equiparação com os testículos (Figura 10) ou com o pênis (Figura 11). A roupa íntima também é usada como metáfora, em que os seios no sutiã estão em igualdade com o pênis na cueca (Figura 12).

Figura 10. Placas de banheiro: Dois pontos no alto de uma porta preta e dois pontos embaixo de outra porta preta

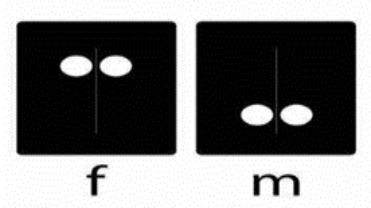

Figura 11. Placas de banheiro: Figura de homem com saliência genital e de mulher com saliências nos seios

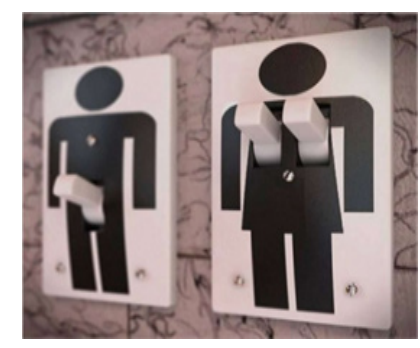


Figura 12. Placas de banheiro: Peças do vestuário sutiã e cueca sobre fundos nas cores creme e cinza

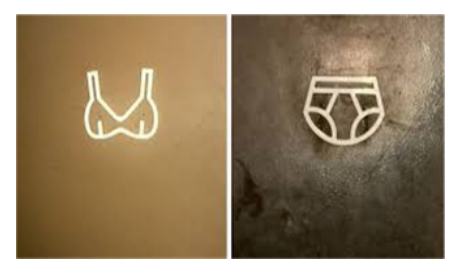

Na contramão dos banheiros generificados, existem placas de sinalização que, como atos de fala, enunciam e dão existência a outros corpos viáveis, reconhecendo outras formas de ser e de estar. Algumas placas têm como foco o uso do banheiro, independentemente de quem o esteja usando. A placa do banheiro unissex (Figura 13) se encontra na Secretaria Municipal de Políticas Sociais de Belo Horizonte, enquanto a placa com a imagem híbrida do feminino/masculino (Figura 14) pertence a uma boate LGBT da capital mineira, local de legitimidade de corpos dissidentes. Já as placas que evidenciam uma concepção de homem e de mulher mais ampla, no intuito de visibilizar a diversidade de corpos e sujeitos (Figuras 15 e 16), foram produzidas no âmbito de uma campanha de 2015, do Conselho Nacional de Combate à Discriminação e Promoção dos Direitos LGBT, divulgada pelo governo federal.

Figura 13. Placa de banheiro: Escrito "Sanitário Unissex" com figuras de mulher e de homem sobre fundo azul

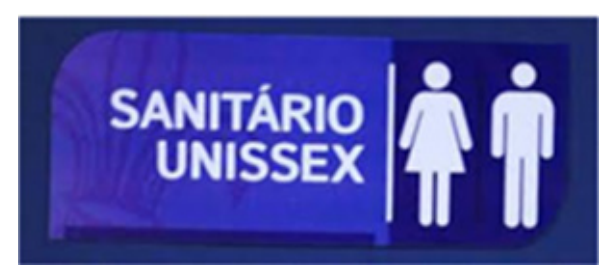

Figura 14. Placa de banheiro: Uma figura metade mulher/metade homem sobre fundo branco

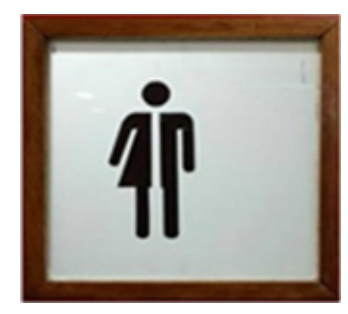

Figura 15. Placa de banheiro: Escrito MULHER e vários adjetivos sobre fundo roxo

\section{MULHER}

TRANS, TRAVESTL, CIS, HitiERO, LESBICA, B1,

ASSEXUAL, NEGRA, BRANCA, COM DEFICIENCLA,

GOROA, MAGRA, ALTA, BAXXA, POBRE, PICA

ESTEE OBANHERRO DE TOOAS

AS MULHERES! 
Figura 16. Placa de banheiro: Escrito HOMEM e vários adjetivos sobre fundo verde

\section{HOMEM}

TRANS, CIS, HE'TERO, GAY, BI, ASSEXUAL,

NEGRO, BRANCO, COM DEFICẼECA.

GOROO, MAGRO, ALTO, BAXXO, POBRE, RICO:

ESTE E OBANHEIRODE TOOOS

OS HOMENS!

O uso dos banheiros, organizados binariamente, por travestis e pessoas trans sinaliza incongruências na normativa sexo/gênero (Butler, 2003) que lá sempre estiveram, mas que foram invisibilizadas e silenciadas pelos sistemas de poder. As subjetividades trans produzem resistências e revelam o não lugar de sujeitos trans na sociedade. Reidel (2013) e Andrade (2015), como pesquisadoras trans, investigam o polêmico uso dos banheiros por travestis e transexuais em escolas. Segundo as autoras, o problema do banheiro é anterior e mais abrangente do que decidir qual banheiro uma estudante travesti deve usar. É uma questão que envolve dimensões no campo dos direitos humanos e da garantia de privacidade e segurança a que toda cidadã brasileira tem direito. O uso do banheiro coletivo por pessoas trans produz efeitos na norma de gênero instituída, desorganizando o modus operandi naturalizado pelo genital e evidenciando outras performances dos corpos. O regime de verdades (Foucault, 1984) é impermeável à diversidade e a seu entorno, reproduzindo um claustro ideológico entre iguais. Todo aquele que não se enquadra na norma institucional simboliza uma ameaça potencial à estrutura organizacional da sociedade, devendo ser repreendido e corrigido, pois seu comportamento torna-se patológico e indesejável.

Outra categoria de banheiro, recém-introduzida em espaços públicos com grande movimentação de pessoas, como shopping centers, é o banheiro família (Figura 17). Essa concepção está interseccionada com idade, maternidade e paternidade, pois visa ao uso por crianças acompanhadas de seus responsáveis, independentemente se um pai leva a filha ao banheiro ou se uma mãe leva o filho ao banheiro. O foco do banheiro, nesse caso, é a proteção da criança.

Figura 17. Placa de banheiro: Escrito "Banheiro Família” com figuras de um pai, uma mãe, um filho e uma filha sobre fundo verde

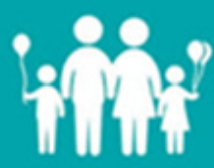

BANHEIRO FAMILIA

Ainda em shopping centers, no caso específico dos banheiros da pessoa com deficiência, o símbolo considerado universal apresenta uma pessoa sentada em uma cadeira de rodas, entretanto não é possível definir o sexo dessa pessoa, pois não existem indícios que demarquem, esteticamente, ser uma mulher ou um homem cadeirante (Figura 18). 
Essa pressuposta assexualidade da pessoa com deficiência é discriminatória, pois reduz o sujeito a uma única característica: a deficiência. "Os demais aspectos que compõem e integram suas subjetividades são desconsiderados, obliterados ou tomados como de menor importância” (Alves, 2017, p. 210).

Figura 18. Placa de banheiro: Figura de um cadeirante sobre fundo azul

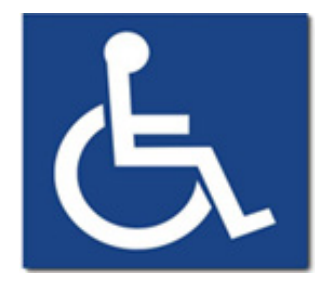

Por fim, o uso de cores para identificar os banheiros é outro aspecto a ser evidenciado, muito comum em placas sinalizadoras usadas em escolas públicas, na lógica do senso comum de que a cor azul é associada ao masculino e a cor rosa, ao feminino (Figura 19).

Figura 19. Placas de banheiro: Escrito "Feminino" com figura de mulher sobre fundo rosa; escrito "Masculino" com figura de homem sobre fundo azul

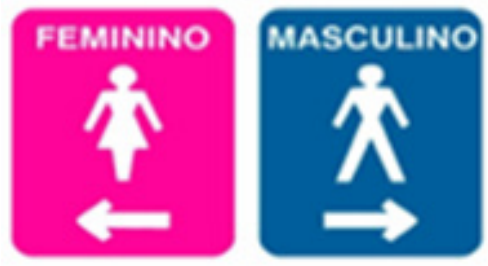

\section{Considerações em trânsito}

O artigo propôs uma reflexão crítica à luz das teorias de gênero sobre a sinalização presente nas placas de banheiros públicos coletivos no Brasil, as quais reiteram o binarismo de gênero ao legitimar um sujeito universal mulher e um sujeito universal homem, identificados pelo sexo anatômico. E, pelo viés exclusivo de determinada anatomia e fisiologia, são definidas as expectativas do que seria o masculino e o feminino, excluindo qualquer leitura de corpos que não se enquadrem no modelo hermeticamente imposto na sociedade. Nesse contexto, corpos trans, mesmo que não queiram, desestabilizam essa normatização ao apresentarem demandas que escapam e revelam outros modos de ser e estar no mundo. Entre a retificação do nome civil e o uso do banheiro generificado por pessoas trans, inúmeras políticas públicas têm sido produzidas no Brasil nos últimos dez anos. Contudo, apesar desse movimento político, persistem as práticas de discriminação sexista e transfóbica. Renomear um corpo trans significa assumir também a fluidez das nomeações. Isso deveria corresponder a espaços públicos não classificados pela lógica binária. 
Representações imagéticas de animais, vestimentas, bebidas, lugares, alimentos, comportamentos e objetos presentes nas placas sinalizadoras de banheiros são tomadas como demarcadores de gênero ao delimitar espaços exclusivos para mulheres e para homens. Entretanto o uso dito tradicional do banheiro generificado não prevê que algumas mulheres tenham pênis nem que alguns homens tenham vagina. Assim, a concepção fundante e falaciosa do universalismo do sujeito homem e do sujeito mulher é usada como referência na designação dos banheiros, desconsiderando formas dissidentes (Preciado, 2017a) de ser mulher e de ser homem.

Para compreender uma determinada realidade social e organizacional por meio de discursos e práticas, o banheiro, como um analisador institucional, denuncia contradições surgidas a partir do binarismo excludente de gênero. Esse espaço arquitetônico, com suas instalações, representações imagéticas e regras de uso não propõe a abertura para a alteridade, sendo hermeticamente fechado em si mesmo e refratário a qualquer fator de desestabilização. Num plano ideal, os banheiros deveriam ser para as pessoas, independentemente de gênero.

\section{Nota}

1 Termo nativo usado para se referir à capacidade de "se passar" por pessoa cis (Cavalcanti, 2016; Jacintho, 2019). 


\section{Referências}

Alves, C. E. R. (2017). Nome sui generis o: nome (social) como dispositivo de identificação de gênero. Belo Horizonte: PUC Editora.

Alves, C. E. R. \& Moreira, M. I. C. (2015). Do uso do nome social ao uso do banheiro: (trans) subjetividades em escolas brasileiras. Quaderns de Psicología, 17(3), 59-69.

Andrade, L. N. (2015). Travestis na escola: assujeitamento e resistência à ordem normativa. Rio de Janeiro: Metanoia.

Baremblitt, G. (1992). Compêndio de análise institucional e outras correntes. Rio de Janeiro: Rosa dos Tempos.

Bento, B. (2012). Sexualidade e experiência trans: do hospital à alcova. Ciência e Saúde Coletiva, 17(10), 2655-2664.

Bourdieu, P. (1997). A ilusão biográfica. In Razões práticas (pp. 183-190). Campinas, SP: Papirus.

Butler, J. (2003). Problemas de gênero: feminismo e subversão da identidade (R. Aguiar, trad.). Rio de Janeiro: Civilização Brasileira.

Butler, J. (2005). Cuerpos que importan: sobre los límites materiales y discursivos del "sexo". Buenos Aires: Paidós.

Butler, J. (2016). Quadros de guerra: quando a vida é passível de luto? Rio de Janeiro: Civilização Brasileira.

Butler, J. (2018). Corpos em aliança e a política das ruas: notas para uma teoria performativa de assembleia. Rio de Janeiro: Civilização Brasileira.

Cavalcanti, C. (2016). Sobre nós (des)organizados: pesquisa-intervenção em Psicologia e o processo de implementação de políticas para pessoas trans* na UFPE. Dissertação de Mestrado, Programa de Pós-graduação em Psicologia, Universidade Federal de Pernambuco, Recife, PE. Csordas, T. (1990). Embodiment as a paradigm for anthropology. Ethos, 18(1), 5-47.

Foucault, M. (1984). História da sexualidade: a vontade de saber (Vol. 1.). Rio de Janeiro: Graal.

Halberstam, J. (1998). Female masculinity. Durham \& London: Duke University Press.

Jacintho, S. (2019). Fora do "Cis"tema: os caminhos da transição de gênero de homens trans. Alabastro: revista eletrônica dos discentes da Escola de Sociologia e Política da FESPSP, 12, 16-31.

Jayme, J. G. (2001). Travestis, Transformistas, Drag-queens, Transexuais: personagens e máscaras no cotidiano de Belo Horizonte e Lisboa. Tese de Doutorado, Programa de Pós-graduação em Ciências Sociais, UNICAMP, Campinas, SP.

Junqueira, R. D. (2010) Currículo, cotidiano escolar e heteronormatividade em relatos de professoras da rede pública. In Fazendo Gênero 9: diáspora, diversidades, deslocamentos. Anais. Florianópolis: Universidade Federal de Santa Catarina. Recuperado de http://www.fg2010.wwc2017. eventos.dype.com.br/resources/anais/1277922201_ARQUIVO_Curriculo,cotidianoescolareheteronormatividade emrelatosdeprofessoras-RogerioDinizJunqueira.pdf.

Kofes, S. (2010). Apresentação. Cadernos Pagu, (6/7), 5-8. Recuperado de https://periodicos. sbu.unicamp.br/ojs/index.php/cadpagu/article/view/1858

Laqueur, T. (2001). Inventando o sexo: corpo e gênero dos gregos a Freud. Rio de Janeiro: Relume Dumará.

Lauretis, T. (1994). A tecnologia do gênero. In H. B. Hollanda (Org.), Tendências e impasses: o feminismo como crítica da cultura (pp. 206-242). Rio de Janeiro: Rocco.

Lourau, R. (1975). Análise institucional. Petrópolis, RJ: Vozes.

Louro, G. L. (1997). Gênero, sexo e educação: uma perspectiva pós-estruturalista. Petrópolis, RJ: Vozes. 
Miskolci, R. (2012). Teoria Queer: um aprendizado pelas diferenças. Belo Horizonte: Autêntica, UFOP.

Oliveira, I. B. \& Maio, E. R. R. (2016). Re/des/construindo in/diferenças: a expulsão compulsória de estudantes trans do sistema escolar. Revista da FAEEBA - Educação e Contemporaneidade, 25(45), 159-172.

Preciado, P. B. (2017a). Basura y género. Mear/cagar, masculino/femenino. In El museo apagado: pornografia, arquitectura, neoliberalismo y museos (pp. 1-3). Buenos Aires: Malba.

Preciado, P. B. (2017b). Manifesto contrassexual: práticas subversivas de identidade sexual. São Paulo: N-1 Edições.

Provimento n. 73, de 28 de junho de 2018. (2018). Dispõe sobre a averbação da alteração do prenome e do gênero nos assentos de nascimento e casamento de pessoa transgênero no Registro Civil das Pessoas Naturais (RCPN). Brasília: Conselho Nacional de Justiça.

Reidel, M. (2013). A pedagogia do salto alto: histórias de professoras transexuais e travestis na educação brasileira. Dissertação de Mestrado, Programa de Pós-graduação em Educação, Universidade Federal do Rio Grande do Sul, Porto Alegre, RS.

Resolução n. 12, de 16 de janeiro de 2015. (2015). Estabelece parâmetros para a garantia das condições de acesso e permanência de pessoas travestis e transexuais - e dá outras providências... Brasília, DF. Recuperado de http://www.lex.com.br/legis_26579652_RESOLUCAO_N_12_DE_16_DE JANEIRO_DE_2015.aspx

Rubin, G. (1975). The traffic in women: notes on the "Political Economy" of sex. In R. R. Reiter (Ed.), Toward an anthropology of women (pp. 157-210). New York, London: Montly Review. Teixeira, A. M. \& Raposo, A. S. (2007). Banheiros escolares: promotores de diferenças de gênero. GT - Gênero, Sexualidade e Educação. In Anped (Org.), Anais da 30 Reunião Anual da Anped. Caxambu, MG: Anped. Recuperado de http://30reuniao.anped.org.br/trabalhos/GT23-3472--Int. pdf. 


\section{CLÁUDIO EDUARDO RESENDE ALVES}

https://orcid.org/O000-0001-9426-7950

Professor da Pós-graduação em Psicopedagogia da Faculdade Pitágoras/BH e Gestor de Políticas Públicas da Secretaria Municipal de Educação de Belo Horizonte.

Endereço: Rua Carangola, 288, $4^{\circ}$ andar, sala 410, Santo Antônio, BH, Minas Gerais, CEP 30330-240.

E-mail: cadupbh@gmail.com

\section{MARIA IGNEZ COSTA MOREIRA \\ https://orcid.org/0000-0003-3602-9609}

Professora Adjunto III da Pontifícia Universidade Católica de Minas Gerais. Bolsista de Produtividade em Pesquisa do CNPq - Nível 2 -Processo n 306109/2019-0.

E-mail: maigcomo@uol.com.br

\section{JULIANA GONZAGA JAYME}

\section{https://orcid.org/0000-0001-5642-6834}

Professora dos Cursos de Ciências Sociais, Cinema e Audiovisual, Publicidade e Propaganda e Arquitetura da Pontifícia Universidade Católica de Minas Gerais. Pesquisadora do CNPq. Processo no. 310477/2019-0

E-mail: julianajayme@pucminas.br

\begin{tabular}{|l|l|}
\hline \multirow{3}{*}{ Histórico } & $\begin{array}{l}\text { Submissão: 01/09/2019 } \\
\text { Revisão: 23/03/2019 } \\
\text { Aceite: 17/07/2020 }\end{array}$ \\
\hline \multirow{3}{*}{ Contribuição dos autores } & $\begin{array}{l}\text { Concepção: CERA, MICM e JGJ } \\
\text { Coleta de dados: CERA, MICM e JGJ } \\
\text { Análise de dados: CERA, MICM e JGJ } \\
\text { Elaboração do manuscrito: CERA, MICM e JGJ } \\
\text { Revisões críticas de conteúdo intelectual } \\
\text { importante: CERA, MICM e JGJ } \\
\text { Aprovação final do manuscrito: CERA, MICM e } \\
\text { JGJ }\end{array}$ \\
\hline Consentimento de uso de imagem & Não se aplica \\
\hline Aprovação, ética e consentimento & Não se aplica \\
\hline \multirow{2}{*}{ Financiamento } & $\begin{array}{l}\text { Bolsa de Produtividade em Pesquisa do CNPq - Nível } \\
\text { Q -Processo n 306109/2019-0 }\end{array}$ \\
\hline
\end{tabular}

